\title{
POSICIONAMENTO DE ENFERMEIRAS SOBRE ENSINO PROBLEMATIZADOR ${ }^{1}$
}

Maria Iracema Tabosa da Silva²

Márcia Caron Ruffino ${ }^{3}$

Mardônio Rique Dias ${ }^{4}$

Silva MIT, Ruffino MC, Dias MR. Posicionamento de enfermeiras sobre ensino problematizador. Rev Latino-am Enfermagem 2002 março-abril; $10(2): 192-8$.

Este artigo constitui a segunda parte de um estudo que tem por objetivo identificar e comparar os escores atribuídos pelas enfermeiras às proposições de curso problematizador antes e após sua participação em capacitação pedagógica problematizadora. Os dados foram coletados através da aplicação de um instrumento adaptado da escala Likert. Os resultados mostraram maior média após a capacitação pedagógica.

DESCRITORES: ensino superior, enfermagem, enfermeiros

\section{NURSES POSITIONING REGARDING THE PROBLEM-BASED APPROACH}

This article presents the second part of a study that aimed at identifying and comparing the scores for the propositions of a problembased course offered to nurses before and after their participation in a capacitation program on the problem-based approach. Data were collected through the adaptation of a Likert's scale. Results showed significant improvements after nurses' participation in the pedagogical capacitation program.

DESCRIPTORS: university education, nursing, nurses

\section{POSICIONAMIENTO DE ENFERMERAS SOBRE LAS VARIABLES DE LA ENSENÃNZA PROBLEMATIZADORA}

Este artículo constituye la segunda parte de un estudio, que tiene por objetivo identificar y comparar los escores atribuidos por las enfermeras a las proposiciones del curso problematizador antes y después de su participación en el curso de capacitación pedagógica problematizadora. Los datos fueron recogidos por medio de la aplicación de un instrumento adaptado de la escala Likert. Los resultados mostraron mayor promedio después de la capacitación pedagógica.

DESCRIPTORES: pregrado en enfermería, enfermería, enfermeros

\footnotetext{
${ }^{1}$ Tese de doutorado apresentada à Escola de Enfermagem de Ribeirão Preto da Universidade de São Paulo, $1999 ;{ }^{2}$ Professor Doutor do Curso de Enfermagem da Universidade Federal da Paraíba; ${ }^{3}$ Professor Titular da Escola de Enfermagem de Ribeirão Preto da Universidade de São Paulo, Centro Colaborador da OMS para o desenvolvimento da pesquisa em enfermagem, e-mail: marciacr@eerp.usp.br; ${ }^{4}$ Professor Doutor do Curso de Psicologia da Universidade Federal da Paraíba
} 
INTRODUÇÃO

$N_{0}$ intuito de compreender e melhor aprofundar as questões relativas às orientações didático-pedagógicas do curso de enfermagem, principalmente às de caráter metodológico, este estudo resgata dois grupos de teorias de classificação( ${ }^{(1)}$, porém de forma prática, conduzindo-as a um processo de aprendizagem que comece e termine nelas próprias.

No primeiro grupo, estão as teorias não-críticas as quais encaram a educação como autônoma e buscam compreendê-la a partir dela mesma ${ }^{(1)}$. Correspondem às seguintes vertentes: pedagogia tradicional, pedagogia nova e pedagogia tecnicista. Neste estudo, as teorias críticas pertencem ao segundo grupo no qual a educação se relaciona dialeticamente com a sociedade ${ }^{(1)}$. Aqui é representada pela vertente da pedagogia problematizadora, expressa através do método do arco, caracterizada, principalmente, pela participação ativa e diálogo constante entre alunos e professores ${ }^{(2)}$.

No Brasil, a organização escolar resistente até hoje, baseiase na tendência liberal tradicional, tendo-se refletido na preparação intelectual, cultural e moral dos alunos, para assumirem sua posição na sociedade. "O compromisso dessa escola é com a cultura, os problemas sociais pertencem à sociedade"(3).

A repercussão desse modelo na enfermagem começa com a enfermagem moderna- normatizada, institucionalizada com roupagem científica na escola fundada por Florence Nightingale, na Inglaterra, em 1860.

Os princípios de organização religiosa e militar permitem inferir sua adequação às características do ensino tradicional, representado por uma educação autoritária, pouco questionadora, centrada nos conteúdos, onde o professor representava a autoridade e o poder, sendo exigido do aluno o domínio dos conteúdos ensinados.

Esse quadro gera uma concepção de educação rígida, dogmática e autoritária, um obstáculo à transformação. Reprime a criatividade e o diálogo comunicativo e concretiza-se num assistencialismo educativo ${ }^{(4-5)}$. A esse respeito, 0 aludido autor acrescenta que, nos métodos de avaliação dos conhecimentos do educando, ocorre uma distância entre educador e educando advindo uma inibição ao pensar verdadeiro.

No final do século passado, o modelo de ensino proposto pela escola tradicional começou a gerar insatisfação, decepção e críticas, resultando na adesão de educadores ao movimento escolanovista europeu e norte-americano. Esse movimento rompe com a sociedade basicamente agrária, pressionando a educação para o trabalho, originando a teoria de educação denominada Pedagogia Nova, Escolanovismo ou Escola Nova ${ }^{(1,6)}$.

A proposta educativa dessa teoria opõe-se à pedagogia tradicional, na medida em que centraliza suas atividades no aluno, despertando nele sentimentos, interesses e espontaneidade. Desenvolve uma pedagogia de inspiração experimental, baseada, principalmente, nas contribuições da biologia e da psicologia, privilegiando o não-diretivismo e enfatizando o ponto de vista pedagógico, com base na atividade do aluno, através da seguinte formulação: "a questão é aprender a aprender"(1).

A vocação era valorizada pela Pedagogia Nova e destacada no curso de enfermagem, a qual era considerada a base dos princípios de idealização de profissão nobre e altruísta. Sua raiz está nos primórdios da enfermagem e, principalmente, no período de sua institucionalização. Esse tema fazia parte da disciplina Ajustamento Profissional ou Ética, onde o aluno recebia orientações para a sua realização pessoal, fundamentadas no sentimento de religiosidade, bem como no compromisso de servir e ter amor pela profissão.

De todo esse quadro, surgiram tentativas, por um lado, de desenvolver-se uma escola nova popular, em momentos históricos diferentes, representada por Freinet, na Europa, e Paulo Freire, no Brasil; por outro, despontava a pedagogia tecnicista que, na enfermagem do Brasil, primava pela competência dos seus alunos, baseada em conteúdos especíicos.

No Brasil, o tecnicismo marca o fim do escolanovismo, tendo como marco 0 advento das Leis Federais ${ }^{(7-8)}$, que regeram o sistema escolar desde o final dos anos 60 até meados da década de 90 , atingindo seu ponto culminante em torno de 1975.

A Lei de Diretrizes e Bases em vigor nessa época (n.5540/ $68)^{(7)}$, que dispunha sobre a reforma do ensino superior, substituiu a matrícula na série pela matrícula em disciplina, tornando complexa a administração acadêmica e acarretando problemas de ordem pedagógica na sala de aula, os quais permanecem até hoje.

É preciso ressaltar que, nessa fase do tecnicismo no ensino, a pedagogia tradicional também esteve presente na prática pedagógica da enfermagem. Além disso, mantinha-se presa aos rigores da disciplina, do conservadorismo e do autoritarismo.

0 marco da pedagogia tecnicista no currículo de enfermagem deu-se com 0 advento do Parecer n.163/72 e da Resolução $n .4 / 72^{(9-10)}$, os quais ressaltaram a necessidade de 0 enfermeiro dominar, cada vez mais, as técnicas avançadas em saúde, tendo em vista a evolução científica, consolidando, assim, o modelo biomédico.

A tendência pedagógica, no momento atual brasileiro, busca não apenas negar as pedagogias classistas tradicionais, mas superálas, conservando seus aspectos técnicos. Nessa perspectiva, deve ser destacada uma das versões que parte da análise da educação com base na realidade do educando, propiciando uma nova proposta filosófica de educação, de mundo e de homem.

Esse enfoque faz-se possível através da utilização da experiência desenvolvida pelos enfermeiros, com a aplicação de uma 
alternativa de ensino que os capacite para o exercício da função de educador. Com isso, estar-se-ia fortalecendo sua habilitação para desenvolver as atividades previstas no Decreto $94.406 / 87^{(11)}$, que regulamenta o exercício da enfermagem, em especial, aquelas contidas nas alíneas $m$ e $n$, inciso II, do art. $8^{\circ}$ : "participação em programas e atividades de educação sanitária, visando à melhoria de saúde do indivíduo, da família e da população em geral; participação nos programas de levantamento e aprimoramento de pessoal de saúde, particularmente nos programas de educação continuada".

$\mathrm{Na}$ vigência das pedagogias de teorias críticas, a enfermagem elaborou sua quarta proposta de currículo mínimo, na qual se destaca "a estreita relação do processo de formação com o processo de trabalho em saúde (da enfermagem e do enfermeiro), cuja prática deve responder às necessidades de saúde da população"(12).

Por outro lado, foi identificada correspondência dessas pedagogias com a atual Lei de Diretrizes e Bases ${ }^{(13)}$, principalmente no que se refere ao desenvolvimento do espírito científico, pensamento reflexivo e crítico, estímulo ao conhecimento dos problemas regionais e outros.

Com base nesses aspectos, considera-se oportuna uma investigação fundamentada numa abordagem de ensino diferente daquela vivenciada pela maioria dos enfermeiros durante sua escolarização. Essa abordagem problematizadora segue a dinâmica do método do arco, promove a aquisição do saber e o desenvolvimento do educando pela valorização do conteúdo vinculado ao contexto histórico, social, cultural e científico.

Nossa hipótese é a de que a participação em curso de capacitação pedagógica, à luz da pedagogia da problematização, modifica a importância atribuída pelas enfermeiras às proposições de curso problematizador (concordância ou discordância com as proposições contidas nos instrumentos).

\section{OBJETIVOS}

- Levantar os escores atribuídos pelas enfermeiras do estudo às proposições de curso problematizador, antes e após a sua participação em capacitação pedagógica problematizadora.

- Comparar os resultados atribuídos pelas enfermeiras participantes do estudo às proposições de curso problematizador, antes de participarem da capacitação pedagógica problematizadora, com os resultados atribuídos após a participação.

\section{MÉTODOS}

O estudo desenvolvido na cidade de João Pessoa - PB, teve como população enfermeiros pertencentes ao quadro de profissionais de um hospital público e que estavam presentes na Semana de Enfermagem de 1998, perfazendo um total de quinze enfermeiras. A amostra foi determinada pela disponibilidade de dez dessas enfermeiras participarem do estudo.

Na elaboração do instrumento, as ações do professor e do aluno, após validação, foram descritas em dezenove proposições, conforme as etapas do método do arco, por representarem a prática pedagógica escolhida para a realização desse estudo. A escala Likert foi adaptada como instrumento de mensuração do valor que as enfermeiras atribuem às proposições do curso problematizador, antes e após sua capacitação na pedagogia da problematização, elaborada conforme 0 seguinte critério: 5 = concordo totalmente; 4 = concordo parcialmente; 3 = não tenho opinião formada; 2 = discordo parcialmente; 1 = discordo totalmente, (anexo 1). Curso problematizador é aqui entendido como aquele em que professor e alunos utilizam a seqüência pedagógica do método do arco.

Foi elaborada, também, uma ficha para levantamento de dados pessoais das enfermeiras, contendo instituição e período de conclusão da graduação em enfermagem, realização de cursos de pós-graduação e de cursos na pedagogia da problematização.

O desenho esquemático a seguir (Figura 1) mostra a dinâmica do procedimento utilizado na aplicação do instrumento, com a escala Likert, onde $R_{1 a}$, chamado de momento diagnóstico, significa as respostas obtidas antes de as participantes vivenciarem o curso problematizador. Conseqüentemente, $R_{2 a}$ significa as respostas obtidas após a participação das enfermeiras no curso problematizador, sendo denominado de momento avaliativo.

\section{Momento \\ diagnóstico \\ CURSO DE CaPácITáÇão PEDÁGÓGIĆ́ PROBLEMATIZÁDORá}

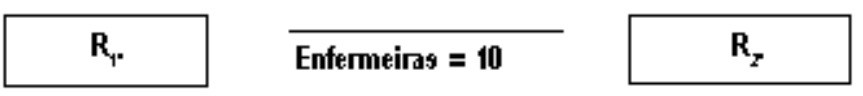

Figura 1 - Metodologia do estudo quanto ao instrumento diagnóstico e avaliativo

O mesmo instrumento constituiu o pós-teste e foi respondido pelas participantes, após a realização da capacitação pedagógica problematizadora. Foi estabelecida uma comparação entre os dados obtidos antes do curso de capacitação pedagógica em planejamento de ensino na educação em saúde- momento diagnóstico $\left(R_{1 a}\right)$, e aqueles obtidos após esse curso - momento avaliativo $\left(R_{2 a}\right)$.

0 que se mediu foram as diferenças entre esses dois momentos, quanto à opinião a respeito de dezenove questões de caráter qualitativo, cuja descrição se encontra nos Anexos 1 e 2, os quais são os instrumentos utilizados para a coleta de dados. 
Convém frisar que a hipótese estabelecida neste estudo é que existe diferença entre esses dois momentos, ou seja, $R_{1 a} \# R_{2 a}$. Foi utilizada a estatística descritiva para efetuar a análise exploratória dos dados. Para a verificação da hipótese, utilizou-se 0 teste $t$ de Student para grupos emparelhados.

\section{RESULTADOS E DISCUSSÃO}

Das dez enfermeiras, quatro concluíram o curso de graduação em enfermagem na EESER, cinco na UFPB e uma na Fundação Regional do Nordeste - FURNE, Campina Grande, atual Universidade Estadual da Paraíba. Sete graduaram-se na década de 80, especificamente, nos anos de 1981,1982 e 1989; uma em 1993 e duas em 1996. Quatro possuem curso de especialização, e as demais são apenas graduadas. Oito estavam participando do curso de capacitação em DST/AIDS, com base na pedagogia da problematização.

Tabela 1 - Distribuição das médias obtidas nos momentos diagnóstico e avaliativo, entre enfermeiros - 1998

\begin{tabular}{ccccccc}
\hline $\boldsymbol{N}^{\mathbf{0}}$ & \multicolumn{5}{c}{ MÉDIÁS } \\
\hline Enf. & $\begin{array}{c}\text { Momento } \\
\text { diagnóstico }\end{array}$ & $\begin{array}{c}\text { Komento } \\
\text { avaliativo }\end{array}$ & $\begin{array}{c}\text { Diferenģa } \\
\text { entre as } \\
\text { médias }\end{array}$ & $\boldsymbol{t}$ & $\boldsymbol{G}$ & $\boldsymbol{P}$ \\
\hline 10 & 3,37 & 4,61 & 1,24 & 4,72 & 09 & 0,001 \\
\hline
\end{tabular}

Destaca-se, na Tabela 1, uma comparação do tipo antes e depois.Os resultados mostraram média de 4,61 no momento avaliativo, sendo a diferença entre os dois momentos de 1,24.

A seguir, foram tomados os escores do instrumento diagnóstico e do instrumento avaliativo e efetuado o teste $t$ de Student, que indicou aumento significativo da média entre os momentos antes e depois da capacitação pedagógica problematizadora. Com isso, não se rejeitou a hipótese de que a participação na capacitação pedagógica, à luz da pedagogia da problematização, modifica a importância atribuída pelas enfermeiras às variáveis qualitativas de um curso problematizador (observação da realidade, pontos-chave, teorização, alternativas de solução e aplicação à realidade).

Nas formulações do pensamento pedagógico de ${ }^{(3,5,14)}$, são encontradas justificativas para a diferença assinalada, ou seja, 0 enfoque metodológico caracteriza-se, principalmente, por desenvolver-se numa relação dialética que envolve o homem e 0 mundo, assim como o enfermeiro e sua realidade, sem dicotomizála. Isso faz distinção com a pedagogia predominante na prática escolar das participantes.
A consciência dessa capacitação pedagógica, entendida como reflexo do meio em que vivem os enfermeiros e sua clientela, foi condição importante para o conhecimento da realidade proposta pelo método do arco. Essa consciência levou o grupo à recuperação e/ou à imaginação de sua história pedagógica, tornando-o responsável por ela e fazendo com que adquirisse uma nova compreensão dos seus conhecimentos, habilidades, atitudes, opiniões e necessidades.

Assim, as técnicas de ensino trabalhadas, o revezamento dos grupos, os textos utilizados e o esclarecimento de dúvidas, no momento da retomada das atividades anteriores a essa capacitação pedagógica, estimularam a atividade e a iniciativa dos grupos, como também valorizaram a instrução enquanto domínio do saber sistematizado e desenvolvimento das capacidades cognitivas das participantes. Por outro lado, propiciaram a vinculação necessária com a temática, levando o grupo a ser cooperativo e a construir um novo conhecimento.

Todos os envolvidos no processo instrucional assumiram o papel de sujeito conhecedor das experiências educativas dos enfermeiros, seus pontos positivos e negativos, ressaltando seus problemas, suas necessidades, suas falhas pedagógicas, teorizando, propondo e aplicando soluções.

Os resultados também se apóiam nas correntes interacionistas, que se opõem à aprendizagem mecânica e se afinam com a seqüência pedagógica do método do arco, considerando a interação entre 0 sujeito e o meio, os quais se transformam reciprocamente.

\section{CONCLUSÕES}

As médias obtidas pelas participantes, na comparação entre o momento diagnóstico e o momento avaliativo, foram estatisticamente maiores no momento avaliativo, ou seja, no pósteste, corroborando a hipótese de que a participação em curso problematizador modifica a importância atribuída pelas enfermeiras às proposições desse tipo de curso.

Dessa forma, os resultados permitem inferir que a introdução do método do arco como estratégia para o ensino dos conteúdos dessa capacitação pedagógica favorece 0 aluno de graduação em enfermagem, tornando-o apto a planejar sessões de educação em saúde, de modo a promover um aprendizado que articule necessidades, experiências, conhecimentos do grupo com o conhecimento sistematizado, técnico-científico, e, assim, facilitar a interação aluno-professor. 


\section{ANEXO 1}

\section{Instrumento diagnóstico}

As proposições abaixo estão relacionadas a uma abordagem alternativa de ensino. Considere a sua experiência em sala de aula, como aluno(a) de enfermagem, e assinale um $\mathrm{X}$ sobre a legenda correspondente à concordância que você atribui a cada uma das proposições.

1. A aula começou com você observando o que existe em seu redor (a realidade)

\begin{tabular}{|c|c|c|c|c|}
\hline $\mathbf{1}$ & $\mathbf{2}$ & $\mathbf{3}$ & $\mathbf{4}$ & $\mathbf{5}$ \\
\hline $\begin{array}{c}\text { Discordo } \\
\text { totalmente }\end{array}$ & $\begin{array}{c}\text { Discordo } \\
\text { parcialmente }\end{array}$ & $\begin{array}{c}\text { Não tenho } \\
\text { opinião formada }\end{array}$ & $\begin{array}{c}\text { Concordo } \\
\text { parcialmente }\end{array}$ & $\begin{array}{c}\text { Concordo } \\
\text { totalmente }\end{array}$ \\
\hline
\end{tabular}

2. Os conteúdos da aula foram extraídos dessa realidade observada por você

\begin{tabular}{|c|c|c|c|c|}
\hline $\mathbf{1}$ & $\mathbf{2}$ & $\mathbf{3}$ & $\mathbf{4}$ & $\mathbf{5}$ \\
\hline $\begin{array}{c}\text { Discordo } \\
\text { totalmente }\end{array}$ & $\begin{array}{c}\text { Discordo } \\
\text { parcialmente }\end{array}$ & $\begin{array}{c}\text { Não tenho } \\
\text { opinião formada }\end{array}$ & $\begin{array}{c}\text { Concordo } \\
\text { parcialmente }\end{array}$ & $\begin{array}{c}\text { Concordo } \\
\text { totalmente }\end{array}$ \\
\hline
\end{tabular}

3. Você teve oportunidade de identificar as causas mais determinantes dessa realidade encontrada

\begin{tabular}{|c|c|c|c|c|}
\hline $\mathbf{1}$ & $\mathbf{2}$ & $\mathbf{3}$ & $\mathbf{4}$ & $\mathbf{5}$ \\
\hline $\begin{array}{c}\text { Discordo } \\
\text { totalmente }\end{array}$ & $\begin{array}{c}\text { Discordo } \\
\text { parcialmente }\end{array}$ & $\begin{array}{c}\text { Não tenho } \\
\text { opinião formada }\end{array}$ & $\begin{array}{c}\text { Concordo } \\
\text { parcialmente }\end{array}$ & $\begin{array}{c}\text { Concordo } \\
\text { totalmente }\end{array}$ \\
\hline
\end{tabular}

4. Você foi estimulado(a) a elaborar um resumo sobre os aspectos observados

\begin{tabular}{|c|c|c|c|c|}
\hline $\mathbf{1}$ & $\mathbf{2}$ & $\mathbf{3}$ & $\mathbf{4}$ & $\mathbf{5}$ \\
\hline $\begin{array}{c}\text { Discordo } \\
\text { totalmente }\end{array}$ & $\begin{array}{c}\text { Discordo } \\
\text { parcialmente }\end{array}$ & $\begin{array}{c}\text { Não tenho } \\
\text { opinião formada }\end{array}$ & $\begin{array}{c}\text { Concordo } \\
\text { parcialmente }\end{array}$ & $\begin{array}{c}\text { Concordo } \\
\text { totalmente }\end{array}$ \\
\hline
\end{tabular}

5. Você foi estimulado(a) a se perguntar sobre o porquê daquilo que foi observado

\begin{tabular}{|c|c|c|c|c|}
\hline $\mathbf{1}$ & $\mathbf{2}$ & $\mathbf{3}$ & $\mathbf{4}$ & $\mathbf{5}$ \\
\hline $\begin{array}{c}\text { Discordo } \\
\text { totalmente }\end{array}$ & $\begin{array}{c}\text { Discordo } \\
\text { parcialmente }\end{array}$ & $\begin{array}{c}\text { Não tenho } \\
\text { opinião formada }\end{array}$ & $\begin{array}{c}\text { Concordo } \\
\text { parcialmente }\end{array}$ & $\begin{array}{c}\text { Concordo } \\
\text { totalmente }\end{array}$ \\
\hline
\end{tabular}

6. Você foi estimulado(a) a utilizar os conhecimentos científicos obtidos no dia-a-dia

\begin{tabular}{|c|c|c|c|c|}
\hline $\mathbf{1}$ & $\mathbf{2}$ & $\mathbf{3}$ & $\mathbf{4}$ & $\mathbf{5}$ \\
\hline $\begin{array}{c}\text { Discordo } \\
\text { totalmente }\end{array}$ & $\begin{array}{c}\text { Discordo } \\
\text { parcialmente }\end{array}$ & $\begin{array}{c}\text { Não tenho } \\
\text { opinião formada }\end{array}$ & $\begin{array}{c}\text { Concordo } \\
\text { parcialmente }\end{array}$ & $\begin{array}{c}\text { Concordo } \\
\text { totalmente }\end{array}$ \\
\hline
\end{tabular}

7. Você e o professor confrontaram a realidade com a teoria

\begin{tabular}{|c|c|c|c|c|}
\hline $\mathbf{1}$ & $\mathbf{2}$ & $\mathbf{3}$ & $\mathbf{4}$ & $\mathbf{5}$ \\
\hline $\begin{array}{c}\text { Discordo } \\
\text { totalmente }\end{array}$ & $\begin{array}{c}\text { Discordo } \\
\text { parcialmente }\end{array}$ & $\begin{array}{c}\text { Não tenho } \\
\text { opinião formada }\end{array}$ & $\begin{array}{c}\text { Concordo } \\
\text { parcialmente }\end{array}$ & $\begin{array}{c}\text { Concordo } \\
\text { totalmente }\end{array}$ \\
\hline
\end{tabular}

8. Você propôs alternativas de soluções

\begin{tabular}{|c|c|c|c|c|}
\hline $\mathbf{1}$ & $\mathbf{2}$ & $\mathbf{3}$ & $\mathbf{4}$ & $\mathbf{5}$ \\
\hline $\begin{array}{c}\text { Discordo } \\
\text { totalmente }\end{array}$ & $\begin{array}{c}\text { Discordo } \\
\text { parcialmente }\end{array}$ & $\begin{array}{c}\text { Não tenho } \\
\text { opinião formada }\end{array}$ & $\begin{array}{c}\text { Concordo } \\
\text { parcialmente }\end{array}$ & $\begin{array}{c}\text { Concordo } \\
\text { totalmente }\end{array}$ \\
\hline
\end{tabular}

9. Nas propostas de soluções você foi estimulado(a) a usar a criatividade

\begin{tabular}{|c|c|c|c|c|}
\hline $\mathbf{1}$ & $\mathbf{2}$ & $\mathbf{3}$ & $\mathbf{4}$ & $\mathbf{5}$ \\
\hline $\begin{array}{c}\text { Discordo } \\
\text { totalmente }\end{array}$ & $\begin{array}{c}\text { Discordo } \\
\text { parcialmente }\end{array}$ & $\begin{array}{c}\text { Não tenho } \\
\text { opinião formada }\end{array}$ & $\begin{array}{c}\text { Concordo } \\
\text { parcialmente }\end{array}$ & $\begin{array}{c}\text { Concordo } \\
\text { totalmente }\end{array}$ \\
\hline
\end{tabular}

10. Você vivenciou as propostas de solução

\begin{tabular}{|c|c|c|c|c|}
\hline $\mathbf{1}$ & $\mathbf{2}$ & $\mathbf{3}$ & $\mathbf{4}$ & $\mathbf{5}$ \\
\hline $\begin{array}{c}\text { Discordo } \\
\text { totalmente }\end{array}$ & $\begin{array}{c}\text { Discordo } \\
\text { parcialmente }\end{array}$ & $\begin{array}{c}\text { Não tenho } \\
\text { opinião formada }\end{array}$ & $\begin{array}{c}\text { Concordo } \\
\text { parcialmente }\end{array}$ & $\begin{array}{c}\text { Concordo } \\
\text { totalmente }\end{array}$ \\
\hline
\end{tabular}

11. Você confrontou as soluções com as características e limitações da própria realidade

\begin{tabular}{|c|c|c|c|c|}
\hline $\mathbf{1}$ & $\mathbf{2}$ & $\mathbf{3}$ & $\mathbf{4}$ & $\mathbf{5}$ \\
\hline $\begin{array}{c}\text { Discordo } \\
\text { totalmente }\end{array}$ & $\begin{array}{c}\text { Discordo } \\
\text { parcialmente }\end{array}$ & $\begin{array}{c}\text { Não tenho } \\
\text { opinião formada }\end{array}$ & $\begin{array}{c}\text { Concordo } \\
\text { parcialmente }\end{array}$ & $\begin{array}{c}\text { Concordo } \\
\text { totalmente }\end{array}$ \\
\hline
\end{tabular}

12. A aula começou com a revisão do assunto anterior

\begin{tabular}{|c|c|c|c|c|}
\hline $\mathbf{1}$ & $\mathbf{2}$ & $\mathbf{3}$ & $\mathbf{4}$ & $\mathbf{5}$ \\
\hline $\begin{array}{c}\text { Discordo } \\
\text { totalmente }\end{array}$ & $\begin{array}{c}\text { Discordo } \\
\text { parcialmente }\end{array}$ & $\begin{array}{c}\text { Não tenho } \\
\text { opinião formada }\end{array}$ & $\begin{array}{c}\text { Concordo } \\
\text { parcialmente }\end{array}$ & $\begin{array}{c}\text { Concordo } \\
\text { totalmente }\end{array}$ \\
\hline
\end{tabular}

13. O professor apresentou a seqüência dos tópicos (roteiro) que constituíram a exposição

\begin{tabular}{|c|c|c|c|c|}
\hline $\mathbf{1}$ & $\mathbf{2}$ & $\mathbf{3}$ & $\mathbf{4}$ & $\mathbf{5}$ \\
\hline $\begin{array}{c}\text { Discordo } \\
\text { totalmente }\end{array}$ & $\begin{array}{c}\text { Discordo } \\
\text { parcialmente }\end{array}$ & $\begin{array}{c}\text { Não tenho } \\
\text { opinião formada }\end{array}$ & $\begin{array}{c}\text { Concordo } \\
\text { parcialmente }\end{array}$ & $\begin{array}{c}\text { Concordo } \\
\text { totalmente }\end{array}$ \\
\hline
\end{tabular}

14. A exposição foi realizada com o desenvolvimento do novo conteúdo

\begin{tabular}{|c|c|c|c|c|}
\hline $\mathbf{1}$ & $\mathbf{2}$ & $\mathbf{3}$ & $\mathbf{4}$ & $\mathbf{5}$ \\
\hline $\begin{array}{c}\text { Discordo } \\
\text { totalmente }\end{array}$ & $\begin{array}{c}\text { Discordo } \\
\text { parcialmente }\end{array}$ & $\begin{array}{c}\text { Não tenho } \\
\text { opinião formada }\end{array}$ & $\begin{array}{c}\text { Concordo } \\
\text { parcialmente }\end{array}$ & $\begin{array}{c}\text { Concordo } \\
\text { totalmente }\end{array}$ \\
\hline
\end{tabular}

15. 0 assunto foi apresentado partindo do simples para o complexo

\begin{tabular}{|c|c|c|c|c|}
\hline $\mathbf{1}$ & $\mathbf{2}$ & $\mathbf{3}$ & $\mathbf{4}$ & $\mathbf{5}$ \\
\hline $\begin{array}{c}\text { Discordo } \\
\text { totalmente }\end{array}$ & $\begin{array}{c}\text { Discordo } \\
\text { parcialmente }\end{array}$ & $\begin{array}{c}\text { Não tenho } \\
\text { opinião formada }\end{array}$ & $\begin{array}{c}\text { Concordo } \\
\text { parcialmente }\end{array}$ & $\begin{array}{c}\text { Concordo } \\
\text { totalmente }\end{array}$ \\
\hline
\end{tabular}

16. A exposição foi enriquecida de recursos didáticos

\begin{tabular}{|c|c|c|c|c|}
\hline $\mathbf{1}$ & $\mathbf{2}$ & $\mathbf{3}$ & $\mathbf{4}$ & $\mathbf{5}$ \\
\hline $\begin{array}{c}\text { Discordo } \\
\text { totalmente }\end{array}$ & $\begin{array}{c}\text { Discordo } \\
\text { parcialmente }\end{array}$ & $\begin{array}{c}\text { Não tenho } \\
\text { opinião formada }\end{array}$ & $\begin{array}{c}\text { Concordo } \\
\text { parcialmente }\end{array}$ & $\begin{array}{c}\text { Concordo } \\
\text { totalmente }\end{array}$ \\
\hline
\end{tabular}

17. O professor promoveu durante a aula a integração do conhecimento, através da comparação do conteúdo novo com o velho, provocando a assimilação

\begin{tabular}{|c|c|c|c|c|}
\hline $\mathbf{1}$ & $\mathbf{2}$ & $\mathbf{3}$ & $\mathbf{4}$ & $\mathbf{5}$ \\
\hline $\begin{array}{c}\text { Discordo } \\
\text { totalmente }\end{array}$ & $\begin{array}{c}\text { Discordo } \\
\text { parcialmente }\end{array}$ & $\begin{array}{c}\text { Não tenho } \\
\text { opinião formada }\end{array}$ & $\begin{array}{c}\text { Concordo } \\
\text { parcialmente }\end{array}$ & $\begin{array}{c}\text { Concordo } \\
\text { totalmente }\end{array}$ \\
\hline
\end{tabular}

18. O professor utilizou durante a aula a informação do aluno para verificar se houve assimilação

\begin{tabular}{|c|c|c|c|c|}
\hline $\mathbf{1}$ & $\mathbf{2}$ & $\mathbf{3}$ & $\mathbf{4}$ & $\mathbf{5}$ \\
\hline $\begin{array}{c}\text { Discordo } \\
\text { totalmente }\end{array}$ & $\begin{array}{c}\text { Discordo } \\
\text { parcialmente }\end{array}$ & $\begin{array}{c}\text { Não tenho } \\
\text { opinião formada }\end{array}$ & $\begin{array}{c}\text { Concordo } \\
\text { parcialmente }\end{array}$ & $\begin{array}{c}\text { Concordo } \\
\text { totalmente }\end{array}$ \\
\hline
\end{tabular}

19. Na aula, o professor sitou o conhecimento num contexto mais amplo

\begin{tabular}{|c|c|c|c|c|}
\hline $\mathbf{1}$ & $\mathbf{2}$ & $\mathbf{3}$ & $\mathbf{4}$ & $\mathbf{5}$ \\
\hline $\begin{array}{c}\text { Discordo } \\
\text { totalmente }\end{array}$ & $\begin{array}{c}\text { Discordo } \\
\text { parcialmente }\end{array}$ & $\begin{array}{c}\text { Não tenho } \\
\text { opinião formada }\end{array}$ & $\begin{array}{c}\text { Concordo } \\
\text { parcialmente }\end{array}$ & $\begin{array}{c}\text { Concordo } \\
\text { totalmente }\end{array}$ \\
\hline
\end{tabular}


ANEXO 2

\section{Instrumento avaliativo}

As proposições abaixo estão relacionadas a uma abordagem alternativa de ensino. Considere esta capacitação pedagógica e assinale um $X$ sobre a legenda correspondente à concordância que você atribui a cada uma das proposições.

1. A aula começou com você observando o que existe em seu redor (a realidade)

\begin{tabular}{|c|c|c|c|c|}
\hline $\mathbf{1}$ & $\mathbf{2}$ & $\mathbf{3}$ & $\mathbf{4}$ & $\mathbf{5}$ \\
\hline $\begin{array}{c}\text { Discordo } \\
\text { totalmente }\end{array}$ & $\begin{array}{c}\text { Discordo } \\
\text { parcialmente }\end{array}$ & $\begin{array}{c}\text { Não tenho } \\
\text { opinião formada }\end{array}$ & $\begin{array}{c}\text { Concordo } \\
\text { parcialmente }\end{array}$ & $\begin{array}{c}\text { Concordo } \\
\text { totalmente }\end{array}$ \\
\hline
\end{tabular}

2. Os conteúdos da aula foram extraídos dessa realidade observada por você

\begin{tabular}{|c|c|c|c|c|}
\hline $\mathbf{1}$ & $\mathbf{2}$ & $\mathbf{3}$ & $\mathbf{4}$ & $\mathbf{5}$ \\
\hline $\begin{array}{c}\text { Discordo } \\
\text { totalmente }\end{array}$ & $\begin{array}{c}\text { Discordo } \\
\text { parcialmente }\end{array}$ & $\begin{array}{c}\text { Não tenho } \\
\text { opinião formada }\end{array}$ & $\begin{array}{c}\text { Concordo } \\
\text { parcialmente }\end{array}$ & $\begin{array}{c}\text { Concordo } \\
\text { totalmente }\end{array}$ \\
\hline
\end{tabular}

3. Você teve oportunidade de identificar as causas mais determinantes dessa realidade encontrada

\begin{tabular}{|c|c|c|c|c|}
\hline 1 & $\mathbf{2}$ & $\mathbf{3}$ & $\mathbf{4}$ & $\mathbf{5}$ \\
\hline $\begin{array}{c}\text { Discordo } \\
\text { totalmente }\end{array}$ & $\begin{array}{c}\text { Discordo } \\
\text { parcialmente }\end{array}$ & $\begin{array}{c}\text { Não tenho } \\
\text { opinião formada }\end{array}$ & $\begin{array}{c}\text { Concordo } \\
\text { parcialmente }\end{array}$ & $\begin{array}{c}\text { Concordo } \\
\text { totalmente }\end{array}$ \\
\hline
\end{tabular}

4. Você foi estimulado(a) a elaborar um resumo sobre os aspectos observados

\begin{tabular}{|c|c|c|c|c|}
\hline $\mathbf{1}$ & $\mathbf{2}$ & $\mathbf{3}$ & $\mathbf{4}$ & $\mathbf{5}$ \\
\hline $\begin{array}{c}\text { Discordo } \\
\text { totalmente }\end{array}$ & $\begin{array}{c}\text { Discordo } \\
\text { parcialmente }\end{array}$ & $\begin{array}{c}\text { Não tenho } \\
\text { opinião formada }\end{array}$ & $\begin{array}{c}\text { Concordo } \\
\text { parcialmente }\end{array}$ & $\begin{array}{c}\text { Concordo } \\
\text { totalmente }\end{array}$ \\
\hline
\end{tabular}

5. Você foi estimulado(a) a se perguntar sobre o porquê daquilo que foi observado

\begin{tabular}{|c|c|c|c|c|}
\hline $\mathbf{1}$ & $\mathbf{2}$ & $\mathbf{3}$ & $\mathbf{4}$ & $\mathbf{5}$ \\
\hline $\begin{array}{c}\text { Discordo } \\
\text { totalmente }\end{array}$ & $\begin{array}{c}\text { Discordo } \\
\text { parcialmente }\end{array}$ & $\begin{array}{c}\text { Não tenho } \\
\text { opinião formada }\end{array}$ & $\begin{array}{c}\text { Concordo } \\
\text { parcialmente }\end{array}$ & $\begin{array}{c}\text { Concordo } \\
\text { totalmente }\end{array}$ \\
\hline
\end{tabular}

6. Você foi estimulado(a) a utilizar os conhecimentos científicos obtidos no dia-a-dia

\begin{tabular}{|c|c|c|c|c|}
\hline 1 & $\mathbf{2}$ & $\mathbf{3}$ & $\mathbf{4}$ & $\mathbf{5}$ \\
\hline $\begin{array}{c}\text { Discordo } \\
\text { totalmente }\end{array}$ & $\begin{array}{c}\text { Discordo } \\
\text { parcialmente }\end{array}$ & $\begin{array}{c}\text { Não tenho } \\
\text { opinião formada }\end{array}$ & $\begin{array}{c}\text { Concordo } \\
\text { parcialmente }\end{array}$ & $\begin{array}{c}\text { Concordo } \\
\text { totalmente }\end{array}$ \\
\hline
\end{tabular}

7. Você e o professor confrontaram a realidade com a teoria

\begin{tabular}{|c|c|c|c|c|}
\hline 1 & $\mathbf{2}$ & $\mathbf{3}$ & $\mathbf{4}$ & $\mathbf{5}$ \\
\hline $\begin{array}{c}\text { Discordo } \\
\text { totalmente }\end{array}$ & $\begin{array}{c}\text { Discordo } \\
\text { parcialmente }\end{array}$ & $\begin{array}{c}\text { Não tenho } \\
\text { opinião formada }\end{array}$ & $\begin{array}{c}\text { Concordo } \\
\text { parcialmente }\end{array}$ & $\begin{array}{c}\text { Concordo } \\
\text { totalmente }\end{array}$ \\
\hline
\end{tabular}

8. Você propôs alternativas de soluções

\begin{tabular}{|c|c|c|c|c|}
\hline 1 & $\mathbf{2}$ & $\mathbf{3}$ & $\mathbf{4}$ & $\mathbf{5}$ \\
\hline $\begin{array}{c}\text { Discordo } \\
\text { totalmente }\end{array}$ & $\begin{array}{c}\text { Discordo } \\
\text { parcialmente }\end{array}$ & $\begin{array}{c}\text { Não tenho } \\
\text { opinião formada }\end{array}$ & $\begin{array}{c}\text { Concordo } \\
\text { parcialmente }\end{array}$ & $\begin{array}{c}\text { Concordo } \\
\text { totalmente }\end{array}$ \\
\hline
\end{tabular}

9. Nas propostas de soluções você foi estimulado(a) a usar a criatividade

\begin{tabular}{|c|c|c|c|c|}
\hline $\mathbf{1}$ & $\mathbf{2}$ & $\mathbf{3}$ & $\mathbf{4}$ & $\mathbf{5}$ \\
\hline $\begin{array}{c}\text { Discordo } \\
\text { totalmente }\end{array}$ & $\begin{array}{c}\text { Discordo } \\
\text { parcialmente }\end{array}$ & $\begin{array}{c}\text { Não tenho } \\
\text { opinião formada }\end{array}$ & $\begin{array}{c}\text { Concordo } \\
\text { parcialmente }\end{array}$ & $\begin{array}{c}\text { Concordo } \\
\text { totalmente }\end{array}$ \\
\hline
\end{tabular}

10. Você vivenciou as propostas de solução

\begin{tabular}{|c|c|c|c|c|}
\hline $\mathbf{1}$ & $\mathbf{2}$ & $\mathbf{3}$ & $\mathbf{4}$ & $\mathbf{5}$ \\
\hline $\begin{array}{c}\text { Discordo } \\
\text { totalmente }\end{array}$ & $\begin{array}{c}\text { Discordo } \\
\text { parcialmente }\end{array}$ & $\begin{array}{c}\text { Não tenho } \\
\text { opinião formada }\end{array}$ & $\begin{array}{c}\text { Concordo } \\
\text { parcialmente }\end{array}$ & $\begin{array}{c}\text { Concordo } \\
\text { totalmente }\end{array}$ \\
\hline
\end{tabular}

11. Você confrontou as soluções com as características e limitações da própria realidade

\begin{tabular}{|c|c|c|c|c|}
\hline $\mathbf{1}$ & $\mathbf{2}$ & $\mathbf{3}$ & $\mathbf{4}$ & $\mathbf{5}$ \\
\hline $\begin{array}{c}\text { Discordo } \\
\text { totalmente }\end{array}$ & $\begin{array}{c}\text { Discordo } \\
\text { parcialmente }\end{array}$ & $\begin{array}{c}\text { Não tenho } \\
\text { opinião formada }\end{array}$ & $\begin{array}{c}\text { Concordo } \\
\text { parcialmente }\end{array}$ & $\begin{array}{c}\text { Concordo } \\
\text { totalmente }\end{array}$ \\
\hline
\end{tabular}

12. A aula começou com a revisão do assunto anterior

\begin{tabular}{|c|c|c|c|c|}
\hline $\mathbf{1}$ & $\mathbf{2}$ & $\mathbf{3}$ & $\mathbf{4}$ & $\mathbf{5}$ \\
\hline $\begin{array}{c}\text { Discordo } \\
\text { totalmente }\end{array}$ & $\begin{array}{c}\text { Discordo } \\
\text { parcialmente }\end{array}$ & $\begin{array}{c}\text { Não tenho } \\
\text { opinião formada }\end{array}$ & $\begin{array}{c}\text { Concordo } \\
\text { parcialmente }\end{array}$ & $\begin{array}{c}\text { Concordo } \\
\text { totalmente }\end{array}$ \\
\hline
\end{tabular}

13. O professor apresentou a seqüência dos tópicos (roteiro) que constituíram a exposição

\begin{tabular}{|c|c|c|c|c|}
\hline $\mathbf{1}$ & $\mathbf{2}$ & $\mathbf{3}$ & $\mathbf{4}$ & $\mathbf{5}$ \\
\hline $\begin{array}{c}\text { Discordo } \\
\text { totalmente }\end{array}$ & $\begin{array}{c}\text { Discordo } \\
\text { parcialmente }\end{array}$ & $\begin{array}{c}\text { Não tenho } \\
\text { opinião formada }\end{array}$ & $\begin{array}{c}\text { Concordo } \\
\text { parcialmente }\end{array}$ & $\begin{array}{c}\text { Concordo } \\
\text { totalmente }\end{array}$ \\
\hline
\end{tabular}

14. A exposição foi realizada com o desenvolvimento do novo conteúdo

\begin{tabular}{|c|c|c|c|c|}
\hline $\mathbf{1}$ & $\mathbf{2}$ & $\mathbf{3}$ & $\mathbf{4}$ & $\mathbf{5}$ \\
\hline $\begin{array}{c}\text { Discordo } \\
\text { totalmente }\end{array}$ & $\begin{array}{c}\text { Discordo } \\
\text { parcialmente }\end{array}$ & $\begin{array}{c}\text { Não tenho } \\
\text { opinião formada }\end{array}$ & $\begin{array}{c}\text { Concordo } \\
\text { parcialmente }\end{array}$ & $\begin{array}{c}\text { Concordo } \\
\text { totalmente }\end{array}$ \\
\hline
\end{tabular}

15. 0 assunto foi apresentado partindo do simples para o complexo

\begin{tabular}{|c|c|c|c|c|}
\hline $\mathbf{1}$ & $\mathbf{2}$ & $\mathbf{3}$ & $\mathbf{4}$ & $\mathbf{5}$ \\
\hline $\begin{array}{c}\text { Discordo } \\
\text { totalmente }\end{array}$ & $\begin{array}{c}\text { Discordo } \\
\text { parcialmente }\end{array}$ & $\begin{array}{c}\text { Não tenho } \\
\text { opinião formada }\end{array}$ & $\begin{array}{c}\text { Concordo } \\
\text { parcialmente }\end{array}$ & $\begin{array}{c}\text { Concordo } \\
\text { totalmente }\end{array}$ \\
\hline
\end{tabular}

16. A exposição foi enriquecida com a utilização de recursos didáticos

\begin{tabular}{|c|c|c|c|c|}
\hline $\mathbf{1}$ & $\mathbf{2}$ & $\mathbf{3}$ & $\mathbf{4}$ & $\mathbf{5}$ \\
\hline $\begin{array}{c}\text { Discordo } \\
\text { totalmente }\end{array}$ & $\begin{array}{c}\text { Discordo } \\
\text { parcialmente }\end{array}$ & $\begin{array}{c}\text { Não tenho } \\
\text { opinião formada }\end{array}$ & $\begin{array}{c}\text { Concordo } \\
\text { parcialmente }\end{array}$ & $\begin{array}{c}\text { Concordo } \\
\text { totalmente }\end{array}$ \\
\hline
\end{tabular}

17. O professor promoveu durante a aula a integração do conhecimento, através da comparação do conteúdo novo com o velho, provocando a assimilação

\begin{tabular}{|c|c|c|c|c|}
\hline $\mathbf{1}$ & $\mathbf{2}$ & $\mathbf{3}$ & $\mathbf{4}$ & $\mathbf{5}$ \\
\hline $\begin{array}{c}\text { Discordo } \\
\text { totalmente }\end{array}$ & $\begin{array}{c}\text { Discordo } \\
\text { parcialmente }\end{array}$ & $\begin{array}{c}\text { Não tenho } \\
\text { opinião formada }\end{array}$ & $\begin{array}{c}\text { Concordo } \\
\text { parcialmente }\end{array}$ & $\begin{array}{c}\text { Concordo } \\
\text { totalmente }\end{array}$ \\
\hline
\end{tabular}

18. O professor utilizou durante a aula a informação do aluno para verificar se houve assimilação

\begin{tabular}{|c|c|c|c|c|}
\hline $\mathbf{1}$ & $\mathbf{2}$ & $\mathbf{3}$ & $\mathbf{4}$ & $\mathbf{5}$ \\
\hline $\begin{array}{c}\text { Discordo } \\
\text { totalmente }\end{array}$ & $\begin{array}{c}\text { Discordo } \\
\text { parcialmente }\end{array}$ & $\begin{array}{c}\text { Não tenho } \\
\text { opinião formada }\end{array}$ & $\begin{array}{c}\text { Concordo } \\
\text { parcialmente }\end{array}$ & $\begin{array}{c}\text { Concordo } \\
\text { totalmente }\end{array}$ \\
\hline
\end{tabular}

19. Na aula, o professor sitou o conhecimento num contexto mais amplo

\begin{tabular}{|c|c|c|c|c|}
\hline $\mathbf{1}$ & $\mathbf{2}$ & $\mathbf{3}$ & $\mathbf{4}$ & $\mathbf{5}$ \\
\hline $\begin{array}{c}\text { Discordo } \\
\text { totalmente }\end{array}$ & $\begin{array}{c}\text { Discordo } \\
\text { parcialmente }\end{array}$ & $\begin{array}{c}\text { Não tenho } \\
\text { opinião formada }\end{array}$ & $\begin{array}{c}\text { Concordo } \\
\text { parcialmente }\end{array}$ & $\begin{array}{c}\text { Concordo } \\
\text { totalmente }\end{array}$ \\
\hline
\end{tabular}




\section{REFERÊNCIAS BIBLIOGRÁFICAS}

1. Saviani D. Escola e democracia: teorias da educação, curva da vara, onze teses sobre educação e política. $24^{\mathrm{a}}$ ed. São Paulo (SP): Cortez; 1991.

2. Díaz-Bordenave J, Pereira AM. Estratégias de ensinoaprendizagem. $18^{\text {a }}$ ed. Petrópolis (RJ): Vozes; 1998.

3.Libâneo C. Democratização da escola pública: a pedagogia críticosocial dos conteúdos. 13ª ed. São Paulo (SP): Loyola; 1995.

4. Freire P. Extensão ou comunicação? $10^{\mathrm{a}}$ ed. Rio de Janeiro (RJ): Paz e Terra; 1992.

5. Freire P. Pedagogia do oprimido. $24^{\mathrm{a}}$ ed. Rio de Janeiro (RJ): Paz e Terra; 1997.

6. Ribeiro MLS. História da educação brasileira: a organização escolar. $14^{a}$ ed. São Paulo (SP): Autores Associados; 1995.

7. Schuch VF, organizador. Lei n. 5.540, de 28 de novembro de 1968. Lei de Diretrizes e Bases da Educação Nacional e o Magistério. $4^{\text {a }}$ ed. Porto Alegre (RS): Sulina; 1972.

8. Schuch VF, organizador. Lei n. 5.692, de 11 de agosto de 1971. Lei de Diretrizes e Bases da Educação Nacional e o Magistério. $4^{\text {a }}$ ed. Porto Alegre (RS): Sulina; 1972.
9. Ministério da Educação e Cultura (BR). Conselho Federal de Educação. Parecer n. 163/72. Currículo mínimo do curso de enfermagem e obstetrícia. Enfermagem, legislação e assuntos correlatos. Fundação Serviços de Saúde Pública. $3^{\mathrm{a}}$ ed. Rio de Janeiro; 1974.

10. Ministério da Educação e Cultura (BR). Conselho Federal de Educação. Resolução n. 4/72. Currículo mínimo do curso de enfermagem e obstetrícia. Enfermagem, legislação e assuntos correlatos. Fundação Serviços de Saúde Pública. $3^{\mathrm{a}}$ ed. Rio de Janeiro; 1974.

11. Conselho Regional de Enfermagem de São Paulo (COREN) (BR). Decreto no.94.406, de 08 de junho de 1987. In: Conselho Regional de Enfermagem de São Paulo (SP). Documentos básicos de Enfermagem: enfermeiros, técnicos, auxiliares. São Paulo; 2001.

12. Ministério da Educação e Cultura (BR). Conselho Federal de Educação. Parecer no. 314/94. Currículo mínimo para o curso de enfermagem. Brasília (DF); 1994.

13. Lei n. 9.394, de 20 de dezembro de 1996. Estabelece as diretrizes e bases da educação nacional. Estado da Paraíba. João Pessoa $(\mathrm{Pb})$ : Secretaria da Educação e Cultura; 1996.

14. Freire P. Pedagogia histórico-crítica: primeiras aproximações. $5^{\text {a }}$ ed. São Paulo (SP): Autores Associados; 1995. 